\title{
Exploring the Effects of Product Placement in Movies and Its Influence on Consumer Behavior-A Case Study of the Transformers Series
}

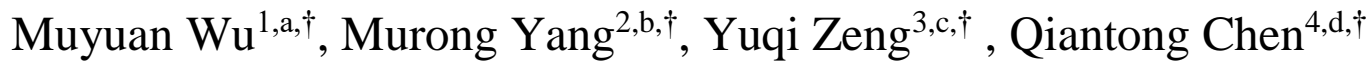 \\ ${ }^{1}$ Department of Cultural, Media and Visual Studies, University of Nottingham, Hefei, Anhui 230000, China \\ ${ }^{2}$ School of Communication, Shandong University of Political Science and Law, Jinan, Shandong 250014, China \\ ${ }^{3}$ College of fine arts, Fujian Normal University, Fuzhou, Fujian 350000, China \\ ${ }^{4}$ Department of Sociology, East China University of Science and Technology, Shanghai 201424, China. \\ *Corresponding author.Email: ${ }^{a}$ arymw7@nottingham.ac.uk, ${ }^{b} 3155851174 @ q q . c o m$,
}

c102092018038@student.fjnu.edu.cn,d278739689@qq.com

These authors contributed equally.

\begin{abstract}
Product placement has been widely acknowledged as a promotional strategy through the international film industry. However, the receptive extent of the audiences might be depended on the genre of placement. Here, we investigate the factors as well as issues relating to the impact of product placement in a specific action movies Transformers Series. Simultaneously, numerous suggestions would be given regarding product placement about status quo of action movies. In this study, mixed methods are used, containing semi-structure interview and questionnaire. Responses are analyzed using the method of thematic analysis, divided into three themes: the effects of product placement on consumer behaviors; the key factor of product placement and its issues; the effect of brand identity. The results confirm that product placements in movies would have an impact on the consumer behaviors of viewers in terms of their spending power and attitudes. The product placement should be closely linked to the key elements of the film. Thus, the plot should be embedded in the film narratively instead of abruptly and bluntly. Apart from that, our results also indicate that the product placement might also contribute to the mercenary environment. Although it has negative effect on the society, they still accept the product placement in good movies. In addition, the study point out that product placement promote the brand exposure, which enhances the audiences recognition via repeating in the film. As for the future product placement in film industry, it is still a crucial advertisements way for products promotion. This study recommends that the brand should pay attention to the form and the audience's feelings in the process of product placement. Moreover, the product embedded degree in the film might be worth of considering for the future motion picture.
\end{abstract}

Keywords: product placement, consumer behavior, attitudes, brand, the Transformer Series

\section{INTRODUCTION}

Product placement is a new form of advertising which develops rapidly of modern media such as movies and television. With the increase of people's demand for movie consumption, advertisers have paid more and more attention to product placement in movies. Compared with traditional advertisements, product placement has natural advantages in marketing because of its characteristic that it can be hidden in plots and dialogues. Generally, product placement in movies does better in disseminating. Consist with the content of the movies organically, it affects the consumption psychology of the audience while promoting the brand. Product placement in movies also improves the brand's popularity and makes advertising more acceptable to the audiences, i.e., leading to the purchasing behavior.

Product placement has a long history and broad development prospects in domestic and foreign movies [1]. Considered to be a double-edged sword, product placement in movies is a carrier of both artistic and 
commercial value that deserves our attention. The existing literatures mainly focused on the quantitative analysis of product placement in movies itself, which provided a broad academic background for our research [2]. Nevertheless, these studies were limited due to the neglect of audience consumption behaviors [3], which can be partially filled in this paper.

Differ from previous studies, our research will adopt a mixed method and focus on its impact on the consumption behaviors of college students in China. Being willing to accept new things, college students are one of the major target group in the consumer market of product placement in movies. The Transformers Series were chosen as our case study because they were wellknown science fiction action movies as a hot Intellectual Property (IP). College students show interest in the series which is conducive to the development of our research.

By studying the views and attitudes of college students on the product placement in the series, we will analyze the factors related to the impact of product placement on audience consumption behavior. Besides, problems of product placement in current action movies are investigated. Additionally, corresponding useful suggestions are proposed for product placement in action movies in future.

The second section presents the methods of this research. Then results based on our analysis of the case study will be illustrated in the third section. The final part describes the findings of our study.

\section{METHOD}

Our study applied mixed methods which combine qualitative and quantitative analysis organically. Thematic analysis has been adopted in the study, which is a method for identifying, analyzing and reporting patterns within data [4]. Semi-structured interview was used to obtain data from respondents' feedback on the Transformers Series.

\subsection{Case Study}

Case studies are widely used in social researches. The objects of the case study can be individuals, groups, organizations, events or certain types of problems [5]. Through extensive collection of relevant materials, the process of research objects' generation and development, internal and external factors and their interrelationships can be understood, sorted out and analyzed in detail. Besides, one is able to form an in-depth and comprehensive understanding and perspectives of relevant issues. We chose Transformers Series as our selecting case in the study. The reason is that the movies not only awakened the memory of the generation under the influence of the corresponding toys since 1984, but also brought the new generation which is the current college students into its impact [6]. In addition, the domestic market for the Transformers Series is prospers [7], showing its super popularity in China by the explosive box office growth rate. As a result, the Transformers Series can be regarded as a representative of science fiction action movies.

\subsection{Semi-structure Interview}

Semi-structured interviews refer to informal interviews conducted according to a rough outline of interviews. This method only has basic requirements for interviewees' conditions and questions to be asked [8]. Compared with structured interviews, semi-structured interviews are more flexible. Moreover, improvisational related questions can be added in the process of interviews. Totally nine college students were selected for semi-structure interviews in our study.

Table 1. Demographic characteristics of our 9 interview participants

\begin{tabular}{llll}
\hline No. & Name & Age & Gender \\
\hline $\mathbf{1}$ & Xiaoxue Nie & 26 & Female \\
$\mathbf{2}$ & Jingcheng Yu & 22 & Male \\
$\mathbf{3}$ & Chunyan Xie & 23 & Female \\
$\mathbf{4}$ & Yuxin Yang & 21 & Male \\
$\mathbf{5}$ & Hujun Yun & 27 & Male \\
$\mathbf{6}$ & Chenxi Lin & 21 & Male \\
$\mathbf{7}$ & Min Wu & 20 & Female \\
$\mathbf{8}$ & Yitong Qian & 22 & Male \\
$\mathbf{9}$ & Yunyao Ma & 21 & Female \\
\hline
\end{tabular}

\subsection{Survey}

With regard to the collection of survey data, a questionnaire covered a total of 11 questions is utilized around the Transformers Series primarily, which is convenient for the respondents to answer the questionnaire quickly. Choosing college students as the respondents of our survey, 110 samples were received totally. We carried out probabilistic statistics analysis of the data received and selected nine semi-structured interviewees according to their willingness expressed in the questionnaire for further interviews. A thematic analysis method for detailed study was applied then.

\section{RESULTS AND DISCUSSION}

\subsection{The Effects of Product Placement on Consumer Behavior}

\subsubsection{Product Placement and Audience Attitude}

After the 1980s, with the rise of film art and the maturity of the gradual integration as well as digital media technology, the organic combination of advertising 
and film has sprung up all over the world [9]. As shown in Figure 1, most people feel acceptable to watching a movie after the product placement.

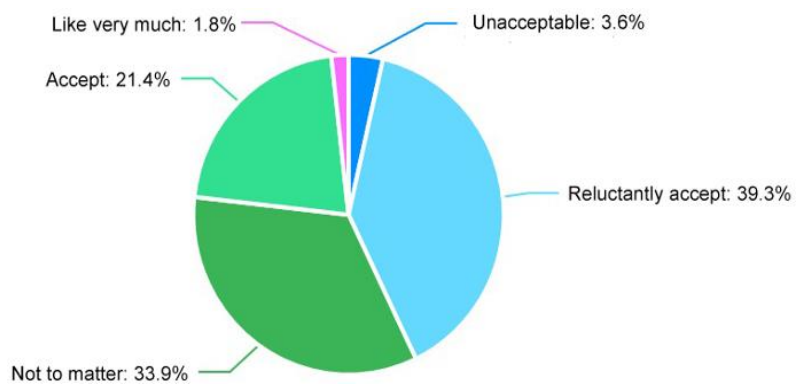

Figure 1 Attitudes towards product placement

According to the Figure 2, 88.2\% people prefer not to abandon the movie because of the product placement, although some of them only reluctantly accepted the product placement.

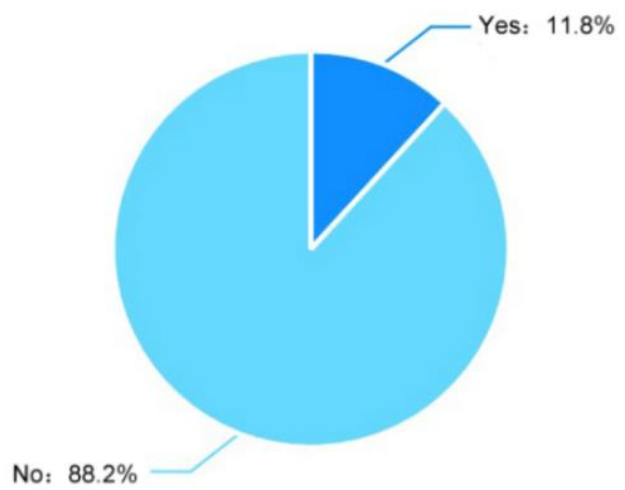

Figure 2 Attitudes towards the ban of product placement

In this case, people are accustomed to this form of propaganda, though it has an impact on feeling of watching the movie. Contemporarily, product placement in movies is becoming more and more common and certain requirements are asserted for the form of it. According to data analysis of our survey (depicted in Figure 3), $57.3 \%$ prefer to Scene while $50.7 \%$ prefer to Plot, which are top two popular forms.

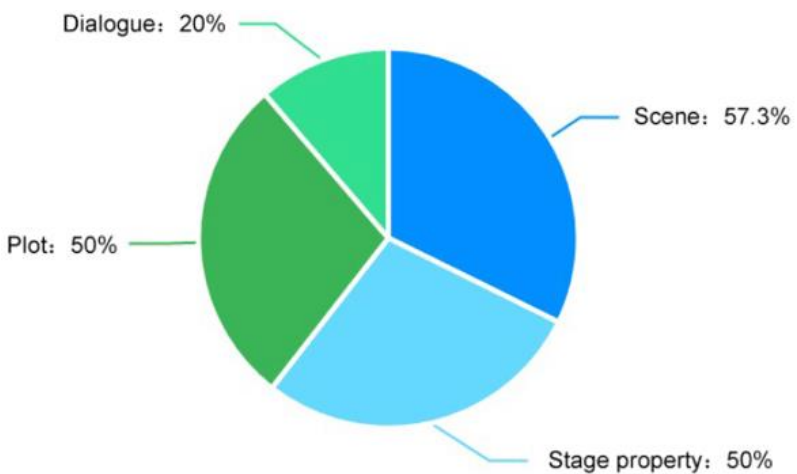

Figure 3 Forms of product placement that are accepted

\subsubsection{Audience Attitude and the Purchase Desire}

Product placement refers to the strategic integration of products or brands, as well as representative visual symbols and even service content into media contents (e.g., movies and TV). Through the reproduction of scenes or plot-based displays, the advertising information is quietly instilled into the audience. On this occasion, the audience will consciously have an impression of the product and brand in an unconscious state, which achieves the purpose of marketing [10]. According to the Figure 4, no matter whether people really like product placement or not, they will leave a deep impression on most audience.

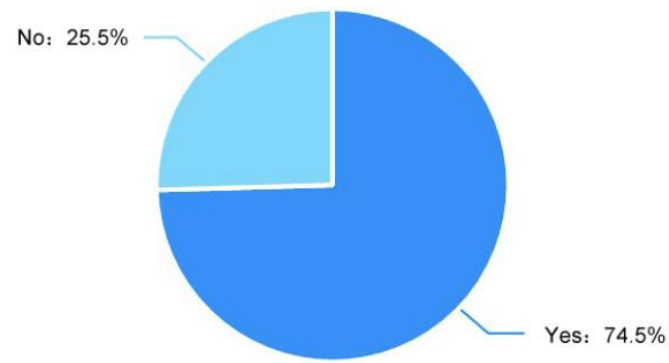

Figure 4 Product Placement deepens the impression of the brand and product

Since the product placement will be displayed clearly anyway, it will leave an impression on the audience. To better analysis, we divide audiences into two different types. First, as for audiences without knowledge of brands or products that appear in the ad placement, they may learn more about them in the future. Second, if the audiences are familiar with the brand or product that appears in it, or interested in the field that related to the product, they will have desires to buy after deepening their impression. They hope that they have the same product as the character and then seeing the brand is also able to think of the plot of the movie. For instance, one of our interviewers Mr. Yang said that he has a special liking for this series and will watch each one. He will have a desire to consume car-related products that appear in the movies due to the interest in automobile field. (Interview with Mr. Yang, online, 2021-02-10)

However, as the saying goes, everything has two sides. The impact of product placement in movies on the purchase behavior of viewers is not all positive. As for advertisements in movies, some forms of product placement will interrupt the audience's viewing continuity to varying degrees and affect the audience's normal acceptance of the movie [11]. Thus, not all advertisements in films will leave a good impression on the audiences. If the form of product placement is too deliberate and leaves a bad impression on the audiences, they will no longer have the desire to buy, but will dislike the brand and product instead. 


\subsubsection{Purchase Desire and Actual Consumption Behavior}

Since the product placement does increase the viewers desire to buy, whether it will eventually produce consumer behavior will also be affected by other factors, which is in line with the Ms. Xie's interview. She said that she wanted to buy the luxury that appeared after watching the Transformers Series. However, because it was too expensive to afford, she was limited in the desire to buy and could not produce the final consumption behavior. Additionally, she also claimed that if the price of the product is within her economic capability, she would like to buy it if necessary. To sum up, the actual needs of the audience is also an important factor that affects the final consumption behavior. To illustrate, if the audience is a student at school, there is neither an urgent need for large-scale high-end durable goods (e.g., automobiles) nor independent economic capacity, i.e., there will be no consumer behavior. Therefore, the emergence of final consumer behavior is still very contingent (Interview with Ms. Xie, online, 2021-02-09).

\subsection{The Key Factor of Product Placement and Its Issues}

\subsubsection{Plot as the Key Factor Embedded in Consumers' Attitudes}

Plot is a crucial factor regarding the acceptance of product placement. It is not only a strategy to create a seamless artifact for producers but also use the type of hybrid method to attract audiences' attentions without knowing the sponsor. Accordingly, the rational plot placement might attract spectators' attention, reaching the maximum of film experiencing between audiences and stakeholders. According to Russel, a brand placement's connection to the plot significantly influences audiences' attention and attitudes towards the placed brand [12]. Highly intense content decides spectators' attitudes directly towards the film and the product, which is also supported by the Miss Nie' $\mathrm{s}$ answering in interview data (Interview with Miss Nie, online, 2021-02-12).

She argued that the placement of the car, Chevrolet Camaro, shows an excellent strategy to integrate the plot and product. Besides, she expressed her motivation that, she always reminded of Bumblebee (Chevrolet Camarp's name in the Transformer Series) whenever she saw the sign of Chevrolet in actual life. Notably, although she realized the advertisement and could not wait to search the information about this company and the car, she consisted that this is not a big deal due to the development of the plot. In the end, she said that if she someday needs to buy a car, she will put Chevrolet at list. Therefore, it seems to present that the image of yellow Bumblebee has already rooted in her mind. Simultaneously, she has already owned purchase intention if she would like to buy a car. In this case, the placement product is not a barrier between audiences and film producers, but an association with the products. A high degree of plot connection can intensify a viewer's perception of the product [13]. Furthermore, a proper plot placement seems to establish a strong association between audiences and advertisers. Thereby, it facialists the retrieval of information about plot connected brands, i.e., motivates spectators' attitudes of purchase towards a product.

\subsubsection{The Issues of Product Placement}

Compared with conventional advertisement, product placement offers a less intrusive and a more subtle way to cut through obvious commercial messages, as analyzed above. Moreover, the product placement is a household strategy in film industry. As Figure 5 illustrates, $74.5 \%$ of participants have realized the product placement in the film during the films playing. This means that distinguishing the product placement embedded in the film is not difficult for viewers. The struggling issue is the form that product placement is presented in the film. Issues about product placement nowadays will be discussed below.

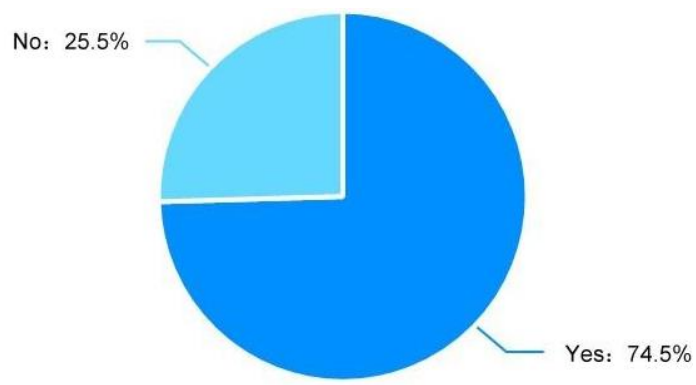

Figure 5 The percentage of recognition towards product placement

Miss Yu points out that she would never accept a film with too much obvious commercial motivations (Interview with Miss Yu, online, 2021-02-12). She gives a specific example that it seems abrupt for a 25 -minute short anime with a very large close-up for a pair of Nike shoes. Based on her answers, the abrupt product placement violates her attitudes toward the film. Therefore, if the brand is deliberate without considering its applicability, it will immediately reduce viewers' goodwill towards the film, letting along the purchase intention towards a product in the film.

Apart from that, the product placement is regarded as a misleading marketing [14]. To adapt the film narrative, the film would be inevitably to cater for the new fashion trending and aesthetics. As Miss Yang states, "if I am interested in a brand in the film, I would draw in diverse methods to buy this although sometime it is a luxury product" (Interview with Miss Yang, online, 2021-0212). Moreover, she also expressed that sometimes she 
feels guilty to buy the luxury but she still cannot help to purchase it, which makes her to think herself fashionable and rich. To illustrate, the product placement has a negative effect for her. The more expensive and extravagant goods the film present, the more purchase intention she will have. Her behavior of purchase has deeply controlled by some expensive goods. This means that product placement can affect people's conscious awareness. Due to its misleading message, it does have some disadvantages for the society, contributing to a mercenary society.

\subsection{Product Placement Impact on the Brand}

\subsubsection{The Relationship between Product Placement and Brand Exposure}

Product placement in films is a great opportunity to enhance brand exposure. They will indirectly get good promotional views from the audience as well as placing the products position in the consumers' mind.

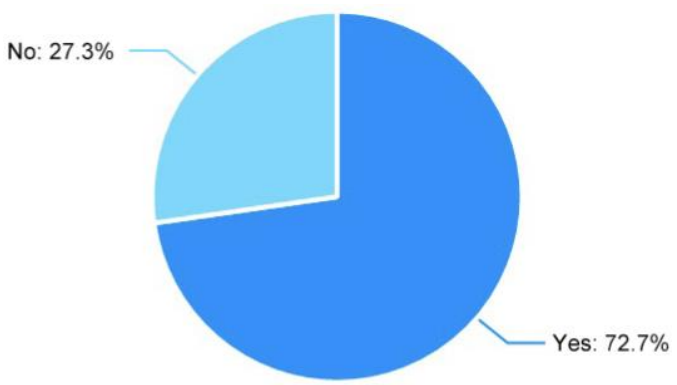

Figure 6 The percentage of audience that have noticed the product placement in the Transformers Series

As exhibited in Figure 6, 72.7\% of the audience did noticed the product placement in the Transformers Series, which indicates that the product placement in the films caught most people's attention.

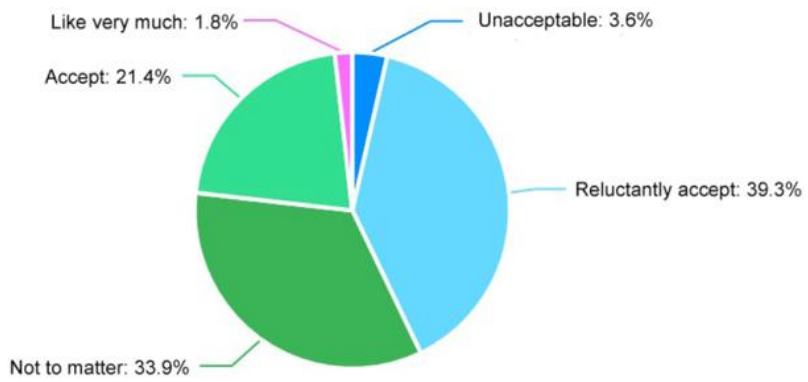

Figure 7 Attitudes towards product placement in the Transformers Series

As illustrated in Figure 7, there are $21.4 \%$ of the audience accept and $39.3 \%$ of the audience reluctantly accept the product placement in the Transformers Series. Besides, $33.9 \%$ of the audience do not care about the product placement. Only $3.6 \%$ of the audience feel the product placement in the Transformers Series unacceptable.
These two figures show the importance of product placement in films. Most audiences will notice the image of product placement in the movie without negative effects on the film itself.

\subsubsection{The Relationship between Exposure and Audience Impressions}

The more exposer the brand gets in the movie, the more memorable it is within the audiences' mind. The brand's exposure in the film determines the depth of memory in the audience's mind. Most interviewees noticed the product placement in the Transformers Series. For example, Mr. Yang, one of our interviewees, said that proper product placement can build the soul of the characters in the film, e. g., AE86 will remind him of Tuohai (Interview with Mr. Yang, online, 2021-02-10).

Almost every interviewee, including girls, mentioned the Chevrolet Camaro, which is the prototype of Bumblebee. Mr. Yang also mentioned that it did well in product placement, considering the feeling of muscle of Camaro suit the character of Bumblebee (Interview with Mr. Yang, online, 2021-02-10). It is a strong evident to support the view.

\subsubsection{The Relationship between Quality of Films and Exposure of Brands}

As radio advertising becomes less and less effective, more and more companies are turning to product placement in films and television to promote their products. Nevertheless, the path to choose a movie suitable for product placement of brands has become a lore. One of the most important things is to choose a good film. Because only a good film can bring good exposure for the brand. Michael Wiles and Anna Danielova mentioned in their event study that 126 product placements in successful films during 2002 reveals a mean cumulative abnormal return of $89 \%$ during the film's opening. It indicates that product placement in a successful film is associated with positive movements in firm stock prices [15]. In addition, as Staff Writer mentioned in his recent article, most of us have become familiar with product placement in movies. Although it's in nearly every major blockbuster, you will roll your eyes every time a film focuses on a irrelevant product in the film [16]. Both of their views prove that proper product placement in a good film can bring substantial economic value.

\section{CONCLUSION}

In summary, it is found that the product placement in movies would have an impact on the consumer behavior of viewers via questionnaire surveys and interviews. Two accounted reasons are the audience's attitude towards the product placement and spending power. In detail, if the 
product placement is closely related to the key elements (e.g., the plot and the scene) of the movie, the audience will be more acceptable. However, due to the different needs and consumption power of the audience group, the audience who desires to buy may not actually buy.

Besides, there are still some problems about placement. The first problem is that obvious commercial placement might decrease audiences' purchase behaviors. Secondly, product placement probably leads to misleading marketing contributed to the mercenary environment. In addition, product placement in films will attract the attention of the audiences anyway, though most of the audiences will not have negative feeling if the movie is satisfactory.

As Hollywood movies began to focus on exploring the Chinese market, there is a growing need for product placement which can provide more possibilities for filmmakers and brands. Therefore, our analysis will be guideline to help movies integrate brands and plots organically. Based on our results, it is suggested that the product placement in movies should maintain a certain principle and bottom line. Forcible product placement in movies which cannot conform to the plot is not recommended. Finally, product placement is ought to respect the content of the movie, i.e., increase the interest of audiences.

\section{REFERENCES}

[1] Li, P, Research on Product Placement Strategies in Commercial Films in China in Recent Ten Years. Modern Marketing (next issue), (11), 2019, 150151.

[2] Wiles, Michael A., Danielova, Anna, The worth of product placement in successful films: an event study analysis. International Retail and Marketing Review, 9(1), 2013.

[3] Nurul H. O., Jalilah J. S., Nur W. R, The Effects of Product Placement in Malaysian Movies and Its Influence on Consumer Behavior. The Asian Conference on Arts \& Humanities Official Conference Proceedings, 2017.

[4] Braun, V, Clarke, V, Using thematic analysis in psychology. Qualitative Research in Psychology, 3, 77-101, 2006.

[5] Liu. J, Wang. T, Gu. C, Jin. Y, et al, Dictionary of Propaganda and Public Opinion, 03, 1993.

[6] Huying Studio, Transformers, soared in controversy and played a triumphal song at the box office, https://www.sohu.com/a/151447116_753519, 2017.

[7] 1905 Film Network, The 1905 film network will launch the Transformers series of four songs, https://www.1905.com/news/20141120/823649.sht $\mathrm{ml}, 2014$.

[8] Kallio H., Pietilä A.M., Johnson M., et al, Systematic methodological review: developing a framework for a qualitative semi-structured interview guide. Journal of Advanced Nursing, 72(12):2954-2965, 2016.

[9] Li, Y, Research on Chinese Film Placement Advertising, Master's degree thesis of Jilin University of the arts, 2016.

[10] Zhang, C, Research on the Problems and Countermeasures of Product Placement Advertising in Film and TV Works-Based on audience response and audience psychology, Master's degree thesis of Lanzhou University, 2015.

[11] Xu, N, Research on Audience Psychology in Film Insertion Advertisement, Master's degree thesis of Hebei University, 2010.

[12] Russell, C. A., Investigating the effectiveness of product placements in television shows: The role of modality and plot connection congruence on brand memory and attitude. Journal of consumer research, 29(3), 306-318, 2002.

[13] McCarty, J. A., Product placement: The nature of the practice and potential avenues of inquiry. The psychology of entertainment media: Blurring the lines between entertainment and persuasion, 45-61, 2004.

[14] Hackley C, Tiwsakul R A, Preuss L, An ethical evaluation of product placement: a deceptive practice?. Business Ethics: A European Review, 17(2): 109-120, 2008.

[15] Wiles M A, Danielova A, The worth of product placement in successful films: An event study analysis. Journal of Marketing, 73(4): 44-63, 2009.

[16] 15 Unforgettable Examples Of Product Placement In Movies, Available at: https://www.fortressofsolitude.co.za/productplacement-movies/, 2017. 